This is the authors' accepted manuscript. The Version of Record was published in Professional Development in Education on 21 September 2019.

McChesney, K., \& Aldridge, J. M. (2019). What gets in the way? A new conceptual model for the trajectory from teacher professional development to impact. Professional Development in Education. https://doi.org/10.1080/19415257.2019.1667412

What gets in the way? A new conceptual model for the trajectory from teacher professional development to impact

\author{
Katrina McChesney ${ }^{1,2}$ and Jill M. Aldridge ${ }^{1}$ \\ ${ }^{1}$ Curtin University, Western Australia \\ ${ }^{2}$ University of Waikato, New Zealand
}

ORCID details

Katrina McChesney: 0000-0002-3991-6265

Jill Aldridge: 0000-0003-0742-0473

\title{
Acknowledgements
}

The research reported in this article was supported by an Australian Government Research Training Programme Scholarship and a Curtin University PhD Completion Scholarship. 


\title{
What gets in the way? A new conceptual model for the trajectory from teacher professional development to impact
}

\begin{abstract}
Although school and education system leaders can mandate teachers' participation in professional development activities, various school-related, teacher-related and studentrelated factors influence the degree to which professional development opportunities ultimately result in the desired teaching and learning impacts. This study examined teachers' perceptions of the factors that influenced the impacts of a range of professional development activities in which they had participated. Constructivist grounded theory analysis of qualitative data provided by 131 teachers (reflecting 15 nationalities) led to the development of a new conceptual model for the trajectory from teacher professional development activities to student impacts. The model involved five stages: intended professional development, received professional development, accepted professional development, applied professional development and student impacts. Various barriers influenced whether professional development was able to progress to each successive stage; the current data provided particular insight into the structural barriers that determined whether intended professional development was actually received by teachers and the acceptance barriers that determined whether received professional development was actually accepted by teachers. The new model extends existing frameworks by highlighting the importance of contextual influences on teacher professional development and providing further specificity regarding some of the gatekeeping factors that influence the outcomes of teacher professional development.
\end{abstract}


A new conceptual model for the trajectory from teacher professional development to impact

Keywords

Teacher professional development, teacher learning, impact, barriers, school improvement, constructivist grounded theory 


\section{What gets in the way? A new conceptual model for the trajectory from teacher professional development to impact}

In the context of widespread global reliance on teacher professional development as a means of improving educational quality, it is essential that we continue to extend our understanding of how professional development activities lead to impacts (Kennedy 2014). In practice, the relationship between professional development activities and subsequent impacts is often weak (TNTP 2015), yet it is precisely for these impacts that professional development typically occurs. The study reported in this article explored teachers' perceptions of what 'gets in the way' - that is, what factors interrupt the trajectory from professional development activities to subsequent impacts. To facilitate consideration of the relationship between professional development and its associated impacts, the term professional development is used here to refer to activities or opportunities for teachers' professional learning, growth or development.

\section{Background}

Teacher professional development is relied upon internationally as a means of educational improvement (Opfer 2016), with huge associated investments of time, money and human resources (TNTP 2015). These efforts are 'driven in no small measure by the global hyper-narrative that tells us (and tells governments in particular!) that improving teacher quality will improve pupil outcomes, which will increase nation-states' economic competitiveness' (Kennedy 2014, p. 691).

This global trend is supported (at least to some extent) by empirical research on the links between professional development activities and teaching and learning impacts. Researchers have sought to provide guidance on best practices as well as the challenges associated with evaluating the impacts of professional development (see, for example, 
Guskey 2000, Desimone 2009, Coldwell and Simkins 2011, Earley and Porritt 2014, King 2014, McChesney and Aldridge 2018, 2019). Drawing on such work, evaluations of particular initiatives have provided inspiring evidence of the potential for teacher professional development to increase teacher knowledge, change teaching practices and improve students' academic and affective outcomes (a few illustrative examples include Timperley et al. 2009, Bishop et al. 2012, Smith 2014). When set alongside the ample evidence that such positive outcomes are not always_-perhaps not even often—realised (Timperley et al. 2007, Yoon et al. 2007, Darling-Hammond et al. 2009, Hill et al. 2013, TNTP 2015, Opfer 2016), these examples of success encourage the continued pursuit of what professional development has to offer.

To increase the impact of professional development, a significant line of past research has investigated key features of the design of professional development that are associated with higher impacts (see, for example, Garet et al. 2001, Timperley et al. 2007, Desimone 2009, Earley and Porritt 2009, Stoll et al. 2012, Barrera-Pedemonte 2016, Opfer 2016). Positive professional development design features emerging from such research include subject-specific curricular focuses, extended and sustained duration, a focus on student learning outcomes, job-embeddedness and opportunities for collaboration and active learning.

Concerningly, however, Hill et al. (2013, p. 476) note that 'disappointing results from recent rigorous studies of programs containing some or all of these features have turned this consensus on its head' (see also Opfer and Pedder 2011). Hill et al. (2013) suggest that ineffective professional development content, poor implementation, inconsistency across multiple sites and poor research designs may be possible explanations for these results. We propose, however, that there is even more at play: A range of additional factors may 'get in the way' such that even well-designed professional development (that is, professional 
development that reflects literature-based design recommendations) does not always lead to the desired teaching and learning gains. Exploring these factors is the focus of the present article.

\section{Literature Review}

This section reviews existing models that link professional development activities and their impacts. Our goal here is to examine what existing models have to say about how professional development activities (can) lead to teaching and learning impacts. As such, we exclude models that provide only lists of aspects for evaluation (Hunzicker 2011, King 2014), models that focus only on classifying or categorising professional development activities (Kennedy 2005, Fraser et al. 2007, Sachs 2011) and models that do not depict how professional development activities relate to teaching and learning impacts (Evans, 2014). Though helpful for other purposes, none of these types of models indicates how professional development activities and their impacts are interrelated.

\section{Existing models of teacher professional development and its impacts}

A majority of the existing models of the teacher professional development process involve sequential or path structures (Loucks-Horsley and Matsumoto 1999, Supovitz and Turner 2000, Guskey 2002, Fishman et al. 2003, Timperley et al. 2007, Desimone 2009, Opfer 2016). These models attempt to show how various teacher and student outcomes follow on from professional development activities. Table 1 summarises the structures of seven sequential models identified within the teacher professional development literature.

The models summarised in Table 1 are relatively similar, most commonly showing professional development activities (ideally) leading to some sort of internal change among teachers, which then leads to external change in the teachers' classroom practice, which, in turn, leads to student impacts. Sequential models of the teacher professional development 
process have been criticised as being overly simplistic (Coldwell and Simkins 2011, Opfer and Pedder 2011, Bates 2013, King 2016, Boylan et al. 2017). However, the number of models reflecting similar trajectories presumably reflects the intuitive acknowledgement that something (or some things) must happen at the teacher level before students are likely to be impacted.

The seven sequential models, though similar, are not identical. Three models omit explicit mention of internal teacher learning or change (Supovitz and Turner 2000, Guskey 2002, Opfer 2016), and one omits mention of external teacher change in terms of classroom practice (Loucks-Horsley and Matsumoto 1999). Two of the models include additional components: Fishman et al.'s model (2003) includes the curriculum as explicitly informing professional development design, and Guskey's (2002) model depicts teachers' attitudes and beliefs as only changing after teachers have seen the effects of new teaching practices on their students' outcomes. Four of the models depict only unidirectional links between adjacent stages (Loucks-Horsley and Matsumoto 1999, Supovitz and Turner 2000, Guskey 2002, Opfer 2016), whereas two models depict bidirectional links (Timperley et al. 2007, Desimone 2009) and another uses a mix of unidirectional and bidirectional links (Fishman et al. 2003). Fishman et al.'s (2003) model is unique in two further respects. First, it contains links between non-adjacent stages, with evidence of student performance (student impacts) linking back to knowledge, beliefs and attitudes (teacher learning / internal change). Second, Fishman et al.'s model forms a complete cycle rather than just a linear path, with knowledge, beliefs and attitudes, enactment (classroom practice) and evidence of student performance each linking back to inform subsequent professional development design.

The sequential models reviewed above are complemented in the existing literature by various non-sequential models (Clarke and Hollingsworth 2002, Opfer and Pedder 2011, 
Table 1. Sequential structures depicted in seven models of the trajectory from teacher professional development to student impacts

\begin{tabular}{|c|c|c|c|c|c|c|c|c|c|c|}
\hline Model & $\begin{array}{l}\text { Background / } \\
\text { context }\end{array}$ & & $\begin{array}{l}\text { fessional } \\
\text { elopment } \\
\text { design }\end{array}$ & & $\begin{array}{l}\text { Teacher } \\
\text { learning } \\
\text { (internal } \\
\text { change) }\end{array}$ & & $\begin{array}{l}\text { Teacher } \\
\text { practice } \\
\text { (external } \\
\text { change) }\end{array}$ & & $\begin{array}{l}\text { Student } \\
\text { impacts }\end{array}$ & $\begin{array}{l}\text { Teacher } \\
\text { beliefs } \\
\text { (internal } \\
\text { change) }\end{array}$ \\
\hline Desimone (2009) & & & $\checkmark$ & $\longleftrightarrow$ & $\checkmark$ & $\longleftrightarrow$ & $\checkmark$ & $\longleftrightarrow$ & $\checkmark$ & $* a$ \\
\hline Fishman et al. $(2003)^{b}$ & $\checkmark$ & $\rightarrow$ & $\checkmark$ & $\longrightarrow$ & $\checkmark$ & $\longleftrightarrow$ & $\checkmark$ & $\longrightarrow$ & $\checkmark$ & \\
\hline Guskey (2002) & & & $\checkmark$ & 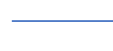 & 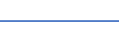 & $\longrightarrow$ & $\checkmark$ & $\longrightarrow$ & $\checkmark$ & $\checkmark$ \\
\hline $\begin{array}{l}\text { Loucks-Horsley and } \\
\text { Matsumoto (1999) }\end{array}$ & & & $\checkmark$ & $\longrightarrow$ & $\checkmark$ & 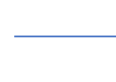 & 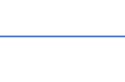 & $\longrightarrow$ & $\checkmark$ & \\
\hline Opfer (2016) & & & $\checkmark$ & & 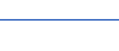 & $\longrightarrow$ & $\checkmark$ & $\longrightarrow$ & $\checkmark$ & \\
\hline Supovitz and Turner (2000) & & & $\checkmark$ & 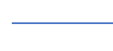 & + & $\longrightarrow$ & $\checkmark$ & $\longrightarrow$ & $\checkmark$ & \\
\hline Timperley et al. (2007) ${ }^{c}$ & & & $\checkmark$ & $\longleftrightarrow$ & $\checkmark$ & $\longleftrightarrow$ & $\checkmark$ & $\longleftrightarrow$ & $\checkmark$ & \\
\hline
\end{tabular}

Notes.

${ }^{a}$ Desimone's model presents changes in terms of teachers' knowledge, skills, beliefs and/or attitudes all at the stage labelled 'teacher learning (internal change)' in the above table

${ }^{b}$ Fishman et al.'s model also contains a feedback link from student impacts to teacher learning / internal change as well as a cyclical structure whereby teacher learning / internal change, teacher practice / external change and student impacts all feed back into the design of subsequent professional development. None of the other models contain such feedback links between non-adjacent stages or use such a cyclical structure.

c Timperley et al.'s model contains additional stages, with both student learning opportunities and students' interpretation and utilisation of available understandings and skills being positioned between external teacher change (classroom practice) and student impacts. 
Cameron et al. 2013). These non-sequential models (reviewed below) are characterised by their different structures and their emphasis on individual teachers' experiences.

Clarke and Hollingsworth's (2002) interconnected model of teacher professional growth involves four domains: the external domain (representing external input such as professional development provision); the personal domain (teachers' knowledge, beliefs and attitudes); the domain of practice (teachers' professional actions and experimentation); and the domain of consequence (teachers' perceptions of salient outcomes). These domains are similar to those used in many of the sequential models reviewed above; however, the interconnected structure of this model highlights 'the complexity of professional growth through the identification of multiple growth pathways between the domains' (Clarke and Hollingsworth 2002, p. 950).

Cameron et al. (2013) and Opfer and Pedder (2011), on the other hand, highlight the context surrounding professional development processes. Opfer and Pedder (2011) draw on complexity theory to detail the multiple ways in which three sub-systems - the teacher, the school and the professional development activity_interact to cause teacher learning. Similarly, Cameron et al. (2013) illustrate how personal, environmental and professional influences intersect with personal and professional needs to shape the teacher-learner's professional journey over time. Unlike the other models reviewed above, both Cameron et al.'s (2013) and Opfer and Pedder's (2011) models consider only one form of impact: teacher learning (internal teacher change).

\section{Gaps and concerns}

Although we now have a wide range of models of the teacher professional development process, gaps and concerns remain in relation to the comprehensiveness of these models. 
First, none of the existing models explains how progression occurs from one stage to the next (Evans 2014, Boylan et al. 2017). This means that we lack the kind of insights that could inform strategic efforts to increase the likelihood that what should happen actually does happen (Timperley et al. 2007). Although we might hope that teacher professional development activities will result in key forms of impact, we know little about how to facilitate those outcomes or what barriers might hinder their realisation.

A second, arguably related, gap, concerns our understanding of how contextual factors influence the progression from professional development activities to subsequent impacts. Although most existing models acknowledge that contextual factors affect the teacher professional development process, there is a need for more clarification around what these factors are, what parts of the process they influence and, in particular, how they exert this influence (Boylan et al. 2017). Those existing models that do provide more detail about contextual factors are limited in that they only consider teacher learning impacts (Opfer and Pedder 2011, Cameron et al. 2013). Moving forward, Cameron et al. (2013, p. 388) argue that 'an improved framework for understanding teacher professional learning must attend to contextual issues' in order for the efficacy of professional development efforts to improve.

Finally, to date, matters of teacher agency have not been adequately addressed in theoretical models of the teacher development process (Boylan et al. 2017). Past work in the field has acknowledged that professional development activities afford differing levels of teacher agency (Kennedy 2005, Kennedy 2014) and that greater levels of agency are likely to be desirable. However, this principle has not yet been integrated into models of the teacher professional development-to-impact process.

We are not the first to identify these gaps and concerns (see, in particular, the review by Boylan et al. 2017), but the research reported in this article goes some way to addressing each of these issues. The next section provides an overview of this research. 


\section{Methods}

\section{Context}

The present research took place within a large-scale public education reform in Abu Dhabi, United Arab Emirates. Education reform efforts in that context have been informed by Western research and practice (Badri and Al Khaili 2014), and Western approaches have been 'parachuted in' (Thorne 2011, Badri and Al Khaili 2014). Drawing on international recommendations, policymakers in Abu Dhabi have enforced extensive professional development for public school teachers in an effort to address system-wide challenges including poor-quality teaching and poor student achievement (Badri and Al Khaili 2014). To sketch the professional development landscape in Abu Dhabi at the time of this study, Figure 1 shows the types of professional development that teachers in the present study reported participating in during the 2013-2014 academic year.

The research reported in this article formed part of a larger study that examined teachers' experiences of professional development in the Abu Dhabi public education reform context (McChesney 2017). The larger study included an investigation of the relationships between the design of professional development activities and their subsequent impacts. However, teachers in the study indicated that a range of other factors (besides the design of professional development activities) influenced the impacts of professional development. The present article draws on data and analysis related to these non-design-related factors.

\section{Participants and Data Collection}

The target population for the study was teachers of English, mathematics and science in public middle and high schools in the emirate of Abu Dhabi. These teachers were known to have experienced similar professional development provision, thus allowing their experiences to be meaningfully compared. This population included both Arab and Western 


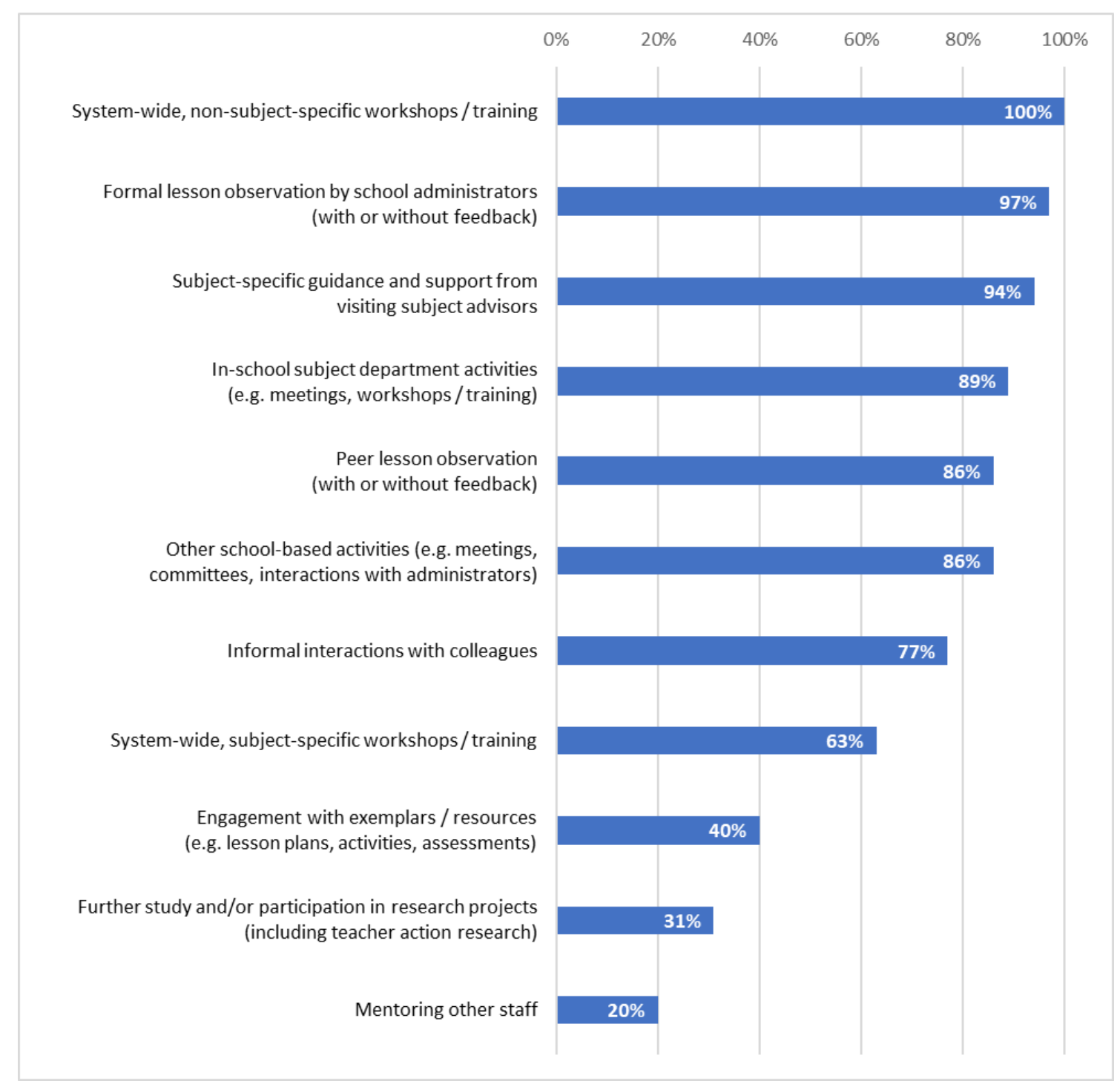

Figure 1. Teachers' reported participation in professional development during the 2013-2014 academic year (based on data provided by the 35 teachers in the interview sample)

teachers, as the Abu Dhabi public education reform strategy involved the recruitment of large numbers of Western, native English-speaking teachers (Badri and Al Khaili 2014).

This article draws on two sets of qualitative data: written comments on a questionnaire (provided by 96 teachers) and semi-structured teacher interviews with 35 teachers. In total, these $N=131$ teachers represented 15 nationalities. Demographic details of the two samples are provided in Table 2. 
Table 2. Demographic details for the questionnaire and interview samples

\begin{tabular}{|c|c|c|c|c|}
\hline \multirow{2}{*}{ Demographic details } & \multicolumn{2}{|c|}{$\begin{array}{l}\text { Questionnaire sample } \\
\qquad(N=96)\end{array}$} & \multicolumn{2}{|c|}{$\begin{array}{c}\text { Interview sample } \\
\qquad(N=35)\end{array}$} \\
\hline & Number & Percentage & Number & Percentage \\
\hline \multicolumn{5}{|l|}{ Gender: } \\
\hline Male & 32 & $33 \%$ & 17 & $49 \%$ \\
\hline Female & 62 & $65 \%$ & 18 & $51 \%$ \\
\hline Not specified & 2 & $2 \%$ & - & - \\
\hline \multicolumn{5}{|l|}{ Cultural background: } \\
\hline Arab & 49 & $51 \%$ & 19 & $54 \%$ \\
\hline Western & 45 & $47 \%$ & 16 & $46 \%$ \\
\hline Not specified & 2 & $2 \%$ & - & - \\
\hline \multicolumn{5}{|l|}{ Teaching subject: } \\
\hline English & 34 & $35 \%$ & 11 & $31 \%$ \\
\hline Mathematics & 43 & $45 \%$ & 12 & $34 \%$ \\
\hline Science & 16 & $17 \%$ & 11 & $31 \%$ \\
\hline Multiple subjects & 1 & $1 \%$ & - & - \\
\hline Not specified & 2 & $2 \%$ & 1 & $3 \%$ \\
\hline
\end{tabular}

The questionnaire comprised quantitative items investigating teachers' perceptions of the impact of professional development (McChesney and Aldridge 2018), but respondents were invited to add qualitative comments at the end of the questionnaire. Of the 393 teachers who completed the quantitative items, 96 provided qualitative comments; only the qualitative comments were relevant to the research reported in this article. The larger questionnaire sample of 393 teachers was designed to reflect the demographic composition of the corresponding population of teachers, but the 96 teachers who chose to provide qualitative comments were, necessarily, self-selected. The questionnaire was provided in both English and Arabic. All Arabic-language responses were translated into English by a bilingual native Arabic speaker.

The teacher interviews $(N=35)$ explored teachers' experiences of professional development in Abu Dhabi public schools, including their perceptions of professional 
development's impacts and the factors contributing to those impacts. The (Western) first author conducted all interviews; she was considered a suitable person to conduct the crosscultural interviews given her extended experience in the Abu Dhabi context (for further details of cross-cultural research considerations associated with the study, see McChesney 2017). Interviews were conducted in English, which was considered to be appropriate given that all teachers in the target population were required to achieve an IELTS score of at least 5.5. Purposive and snowball sampling (Cohen et al. 2007) were used to ensure that the interview sample reflected the experiences and perspective of a range of teachers. Interviewing continued until Seidman's (2006) criteria of sufficiency and saturation had both been reached. All interviews were audio-recorded and transcribed in full.

\section{Data Analysis}

Data analysis involved constructivist grounded theory methods (as described by Charmaz 2000, 2003, 2006, 2008). Charmaz modified traditional grounded theory methodology (as defined by Glaser and Strauss 1967, Strauss and Corbin 1994), advocating a constructivist epistemology that involves consideration of the underlying motivations, beliefs and other influences that affect people's observable behaviour and speech. Further, Charmaz moved away from grounded theory's traditional search for universally applicable theories, arguing that 'understanding must be located in the studied specific circumstances of the research process' (Charmaz 2008, p. 398).

For the present study, themes were identified within the interview and survey data through constant comparative analysis both during and following data collection (Charmaz 2000, 2003, 2006, 2008). Coding of themes was iterative and used inductive code names generated from the raw data. Emerging themes were triangulated across both the data sets (interview and survey responses). After the full set of themes had been identified, the development of the conceptual model involved searching for possible groupings and 
connections among these themes. Various groupings of themes were trialled as well as various ways of arranging these groupings and depicting their interactions, including sequential and non-sequential arrangements.

Throughout this process, data analysis was seen 'as a construction that not only locate[d] the data in time, place, culture and context, but also reflect[ed] the researcher's thinking' (Charmaz 2003, p. 313, see also Willis 2007). Thus, in interpreting teachers' contributions, while seeking to understand teachers' constructed meaning around professional development, the first author also drew on her own experiences in the Abu Dhabi context as well as on existing theory. Memo writing, including extracts of raw data, was used throughout all stages of this process to document the first author's growing understanding of the meaning contained in the data and the emerging links between the raw data, the themes, and the researcher's own experiences and knowledge of existing theory (Charmaz 2003).

Ultimately, a sequential arrangement of themes was identified that captured all the identified themes satisfactorily and also captured the apparent interactions among the groupings of themes. This arrangement was therefore proposed as a new conceptual model of the teacher professional development to impact trajectory.

\section{Results}

\section{The New Conceptual Model}

The result of the analysis reported above was a contextually situated grounded theory, summarised in a visual depiction of a conceptual model (see Figure 2) that reflected the first author's construction of meaning related to teachers' experiences of professional development within the specific context of Abu Dhabi public schools. The new model acknowledges the barriers that teachers identified and depicts how, in teachers' views, these barriers intersected with the professional development-to-impact process. 


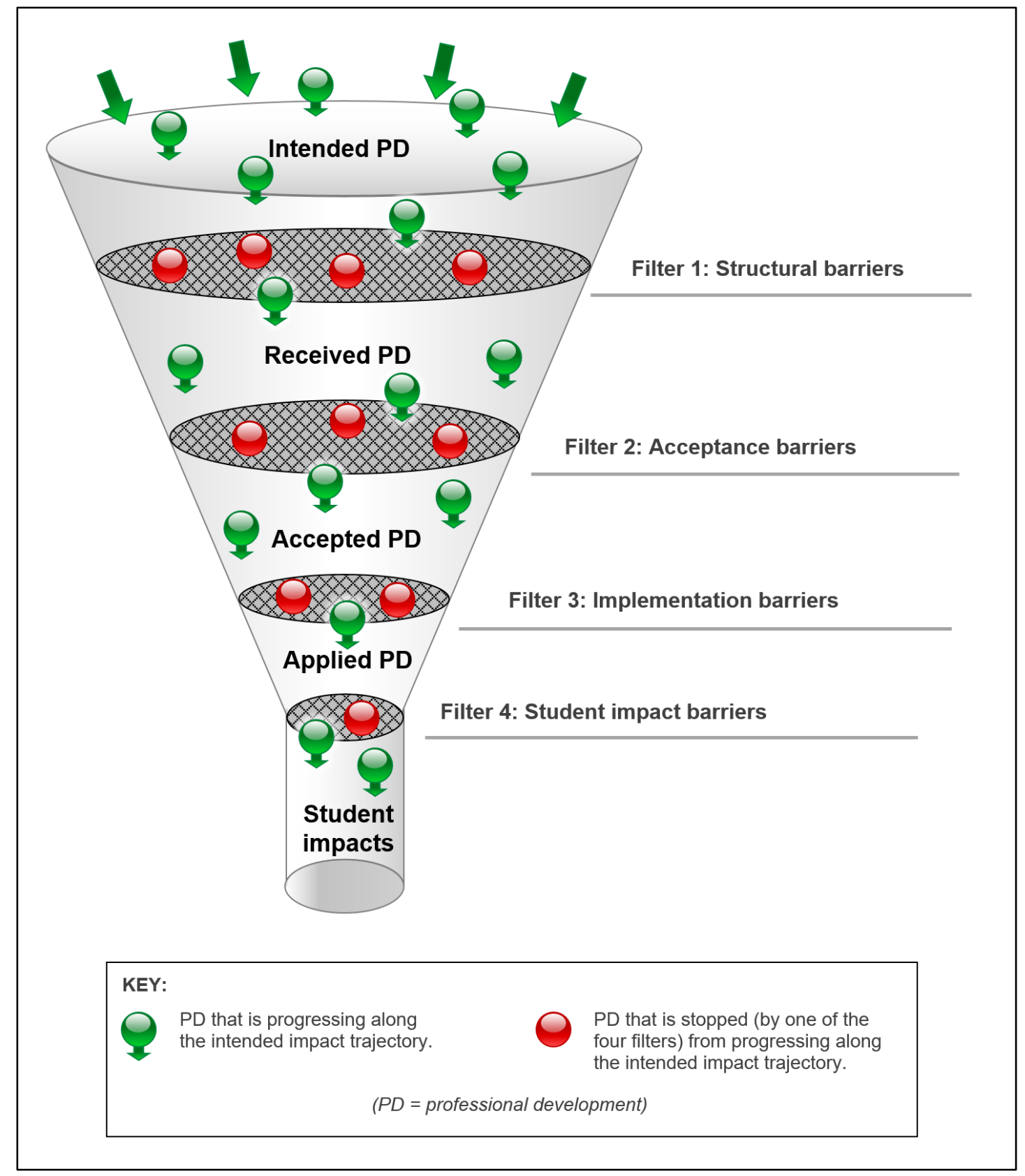

Figure 2. Conceptual model of the professional development-to-impact trajectory and the filters that restrict progression through the intended trajectory

The model shows professional development progressing through five stages, ideally culminating in student-level impacts. These stages are:

- Intended professional development - the planned professional development that teachers were intended to experience; 
- Received professional development - the professional development that teachers actually experienced;

- Accepted professional development - the professional development that teachers had both received and accepted;

- Applied professional development - the professional development that was applied in teachers' classroom practice; and

- Student impacts - the professional development that had positive effects on students (e.g. their learning, attitudes, motivation or engagement).

This trajectory differs from past models of the teacher professional development process, which generally indicate progression from professional development activities to teacher learning, classroom implementation and then student impacts (see literature review). The intended, received and accepted professional development stages are unique to this model; the applied professional development (classroom practice) and student impacts stages align with components of other models.

The data indicated that this trajectory was influenced by a number of barriers, depicted in the conceptual model (Figure 2) as filters that lie between the stages. These barriers successively reduced the amount of professional development progressing through the intended impact trajectory. That is, not all of the intended professional development became received professional development; not all of the received professional development became accepted professional development; not all of the accepted professional development became applied professional development; and not all of the applied professional development resulted in student impacts.

The present study allowed the identification of two types of structural barriers (language issues and school-related factors) that prevented some teachers from accessing some of the intended professional development; these structural barriers were identified as 
forming the first filter. Similarly, three types of acceptance barriers (cognitive access, contextual fit and teacher agency) were identified as having prevented some of the received professional development from being accepted by teachers.

Two further filters were depicted in the conceptual model: implementation barriers, which prevented received professional development from being applied in teachers' classroom practice, and student impact barriers, which prevented teachers' classroom changes from affecting students. Although the data provided by teachers in this study did not provide insights regarding the specific nature of the implementation and student impact barriers, these two filters were included in the conceptual model for completeness, informed by the existing literature (reviewed earlier). Further probing the nature of these filters is a pressing direction for further research (see Limitations).

The sections that follow provide more details about the barriers making up the first two filters in the conceptual model. In doing so, the numbers of teachers reporting the various barriers are reported. These numbers should not be over-interpreted since the teachers were not asked about each distinct barrier in order to establish frequencies. Nonetheless, these numbers provide some indication of the relative importance of issues, such as where large numbers of teachers within the sample spontaneously shared their experiences of a common issue despite this not being directly prompted in the data collection.

\section{Structural Barriers}

The first filter, structural barriers, prevented some of the intended professional development from being received by teachers. There were two types of structural barrier:

- School-related factors that prevented teachers from attending professional development; and

- Language issues when professional development was conducted in a language that teachers were not able to understand. 
These barriers are described below. It should be noted that since the intended professional development for all teachers in the target population of this study was consistent, differences in received professional development were interpreted as being due to barriers rather than differing policy intentions.

\section{School-Related Factors}

Some teachers reported that their access to the intended professional development was affected by school-related factors including school timetabling, the school's physical location and teachers' assigned grade levels or teaching subjects. In terms of school timetabling, some teachers' access to professional development was restricted due to professional development activities occurring while the teacher was teaching (16 teachers) or at times when teachers were too tired or busy to engage fully (18 teachers). In terms of the school's physical location, some teachers in rural schools felt that they had received less professional development than their counterparts in urban schools (6 teachers). In terms of teachers' assigned teaching subjects and grade, teachers reported that subject-specific forms of professional development were more common for teachers of certain subjects or grade levels, thus disadvantaging teachers of other subjects or grade levels (20 teachers).

\section{Language Issues}

The language used in professional development was a second structural barrier that prevented some teachers from accessing professional development. Language issues appeared to be particularly problematic for in-school, whole-school professional development activities involving both Arabic- and English-speaking teachers. In some schools, these activities were conducted predominantly in Arabic, with Western teachers being provided with supporting English language translation (9 teachers). However, the extent of this English translation ranged from complete, parallel translation to only brief summaries of key messages. In other 
schools, the in-school, whole-school professional development was conducted entirely in Arabic, with no provision for non-Arabic-speaking staff (8 teachers).

Language appeared to be less problematic for other forms of professional development, with just two teachers reporting language-related access issues outside the inschool, whole-school professional development sessions. One Western teacher reported a language barrier in relation to formal lesson observation and feedback by (Arab) school administrators, and one Arab teacher reported struggling to understand exemplar teaching and assessment materials that were in English. On the other hand, two Western teachers who spoke no Arabic reported nonetheless being able to learn a great deal from observing their Arab colleagues' lessons ( 1 teacher) and from school leadership meetings ( 1 teacher) that were conducted entirely in Arabic. These teachers described observing body language and other cues to construct meaning.

Overall, the results indicated that despite standardised policy intentions for professional development provision, school-related factors and language issues prevented some teachers from accessing the intended professional development. As such, these structural barriers formed the first filter in the conceptual model of the teacher professional development impact trajectory.

\section{Acceptance Barriers}

The second filter shown in Figure 2, acceptance barriers, prevented some of the received professional development from being accepted by teachers. Although existing models emphasise teacher learning (Guskey 2000, Fishman et al. 2003, Timperley et al. 2007, Desimone 2009, King 2014), the present study suggested that after teachers received professional development, the gatekeeper for subsequent impact was whether teachers accepted the professional development content.

Three types of acceptance barrier were identified in the data: 
- Teachers' cognitive access to professional development;

- The perceived fit of professional development for the contexts in which teachers worked; and

- Matters related to teacher agency.

Each of these barriers is described below.

\section{Cognitive Access}

The first type of acceptance barrier involved teachers' ability to understand and construct meaning related to the ideas and approaches that they encountered within professional development activities. This cognitive access barrier appeared to specifically affect the Arab teachers, as there was a cultural and conceptual gap between these teachers' existing worldviews, practices and professional knowledge and the new (Western) approaches that were reflected in professional development.

Arab teachers in the study noted that the learning and change being expected of them were substantial (9 teachers). (In contrast, the Western teachers felt very familiar with the pedagogical approaches being promoted.) Some Arab teachers reported feeling overwhelmed or exhausted as a result of the pace and scale of the change required ( 3 teachers). Another Arab teacher described struggling to keep up with the change:

It was a rush of information, with no time to implement, to apply, to test ... We need to focus on something, and we need to have some time to understand, to apply, to test, to evaluate, to reflect, before going to another [topic]. (Int-Ar-14)

This teacher's remark followed a full year of weekly professional development on a single theme, suggesting that the issue related to cognitive access rather than either a shortage of professional development or an overabundance of competing topics. 
Arab teachers described the professional development they had received as being too theoretical and not sufficiently linked to classroom practice (10 teachers). For example, after attending 30 hours of differentiation training, one Arab teacher said:

Actually, I still need more [professional development] about differentiation even now, because I think that [my understanding of differentiation] is still theoretical, not practical. (Int-Ar-01)

The Arab teachers particularly struggled to make sense of new ideas when the professional development had not been directly aligned to their particular teaching subject or grade level (8 teachers); they, therefore, preferred subject-specific professional development (9 teachers).

Relatedly, the Arab teachers expressed that practical forms of professional development were more helpful than theoretical approaches in allowing them to understand new teaching strategies. They wanted model lessons (5 teachers), exemplar teaching resources or plans (5 teachers) and in-class coaching ( 8 teachers) to illustrate the new approaches, and they valued interactions with their peers ( 2 teachers) and support from subject advisors (3 teachers) because of the specific, practical support involved.

Overall, the data suggested that the Arab teachers' cognitive access to professional development was restricted due to a cultural and cognitive gap between the teachers' existing knowledge and skills and the pedagogical approaches involved in the professional development. Making sense of these foreign pedagogies and practices was challenging for the Arab teachers, preventing them from accepting and thus moving forward with some of the received professional development.

\section{Contextual Fit}

The second type of acceptance barrier identified in this study involved teachers' perceptions of the contextual suitability of professional development. Teachers indicated that 
for them to accept professional development, its content needed to 'fit' their student, school and wider cultural contexts.

Some teachers (both Arab and Western) felt that the ideas and strategies advocated during professional development were not suitable for their students. Reasons given for this lack of fit included students' attitudes (6 teachers), behaviour (6 teachers), poor English language proficiency (8 teachers) and low academic abilities (10 teachers),

Some teachers rejected the content of professional development because of schoollevel factors: school leaders failing to support behaviour management ( 5 teachers) and either lacking understanding (4 teachers) or being unaware (4 teachers) of the pedagogical approaches advocated in professional development. For example, one teacher (Int-We-05) reported that his principal was 'very focused on whether or not your students are fairly quiet. He doesn't mind if they work in groups, but he wants a well-structured classroom.' This teacher went on to admit that his teaching decisions were, to some extent, compromised by 'the reality, which is, I have to control these students and not let them run wild.'

At a wider cultural level, teachers indicated that it was inappropriate to simply transfer teaching approaches from other parts of the world to the Abu Dhabi context (8 teachers). Teachers rejected professional development that they felt was 'inapplicable' (IntWe-02) or 'not real[istic]' (Int-Ar-08) for Abu Dhabi public schools or that had been led by personnel who, in the teachers' opinion, lacked the cultural and contextual knowledge necessary to inform their work (5 teachers).

Overall, these issues with the contextual fit of professional development affected teachers' acceptance of the content of that professional development. As such, these issues prevented some of the received professional development from becoming accepted professional development.

\section{Teacher Agency}


The final type of acceptance barrier identified in the study involved matters of teacher agency. The teachers valued being respected as professionals and having opportunities to exercise professional agency; when this was not the case, they were more likely to reject the ideas and approaches involved in professional development.

The teachers in the present study expressed strong perceptions of their existing expertise (32 teachers). As such, the teachers were frustrated when professional development involved content that they felt was not new for them (30 teachers) or when they were refused permission to participate in activities that they felt would have been beneficial for their professional learning (10 teachers). The teachers called for future professional development to be differentiated according to teachers' needs and proficiencies ( 8 teachers).

The teachers were also frustrated by professional development being delivered by personnel whom the teachers did not perceive to be sufficiently skilled or qualified (14 teachers). In contrast, they highlighted the value of professional development that occurred through informal collaboration with their peers, whom they generally perceived as holding significant expertise (31 teachers).

When teachers were able to exercise their professional agency in selecting professional development, they reported greater associated benefits and impacts ( 9 teachers). Although 7 teachers indicated that they would prefer not to participate in professional development at all, most teachers indicated that they valued and wanted professional development - provided that they could have input into both the types and the topics of the professional development that they would participate in. One teacher stated that:

We can't forget that we are adults and there has to be a choice in order to engage the learner within the teacher. A teacher has to be able to have a choice in the learning they want to engage in. (Int-We-04) 
Regardless of whether professional development activities were compulsory or selfselected, teachers exercised agency by actively critiquing professional development content against their existing knowledge, beliefs and practices. One teacher explicitly described only accepting and progressing the ideas presented in professional development 'if I agreed with [them]' (Int-We-01). Teachers reported filtering professional development on the basis of their existing philosophies of teaching (14 teachers) as well as the fit of the professional development for their teaching context (14 teachers) or their teaching subject (15 teachers). Thus, despite the policy mandates for extensive pedagogical change, teachers appeared to retain self-determination and professional autonomy over their practice. According to one teacher, 'We have to be selective ... you know, it's teachers' "sixth or seventh sense"' (IntAr-02).

Overall, the data indicated that when teachers felt that their agency or expertise were not appropriately acknowledged, they exercised their agency by rejecting the content of the received professional development. This prevented professional development from progressing along the intended impact trajectory.

\section{Discussion}

The research reported in this article investigated teachers' perceptions of the factors (other than the design of professional development) that influenced the impact of the professional development that they had participated in during one academic year.

Although the study took place in a specific local context, the sample comprised teachers from 15 Arab and Western countries, including countries such as the US and UK that have, to date, been the origins of much of the teacher professional development literature. In addition, the $N=131$ teachers' accounts related to a wide range of professional development activities (see Figure 1), many of which were similar to those that have been documented as forming part of teacher professional development efforts in other international 
contexts (OECD 2009). As such, the findings reported in this article may offer relevant insights for teacher professional development efforts elsewhere provided that care is taken in generalising to any new context. Those wishing to draw on the findings of the present study in another context should consider the degree of similarity between the Abu Dhabi context and the proposed new context, in line with standard procedures for generalising the findings of interpretivist research (Lincoln and Guba 1986, Willis 2007).

\section{Significance of the New Conceptual Model}

Despite a proliferation of models of the teacher professional development process, the field as a whole has been described as under-theorised (Evans 2014, Kennedy 2014). Our new conceptual model is distinct from existing models in two important ways, meaning that it may help extend the theorisation of professional development. First, our model was informed by data that reflected teachers' perceptions of what actually happened in relation to the impacts of professional development. Our model thus differs from past models that have primarily emerged from theorising about what we think should happen. Second, the new model depicts how progression among the stages of the model occurs and offers insights into what can 'get in the way'. This progression has been largely un-addressed in existing literature (Evans 2014, Boylan et al. 2017).

To build on the present study, further studies should continue to investigate what actually happens in terms of the impacts of professional development activities, examining whether the stages and filters in our model seem relevant in other contexts. Such research could incorporate the accounts of school leaders, professional development providers and students as well as teachers.

This model was primarily designed to capture teachers' experiences in the Abu Dhabi context. Some of the specific structural and acceptance barriers that were identified in the present study may, therefore, tell us more about the nature of professional development 
provision in Abu Dhabi than they do about what might contribute to the impact of professional development in other contexts. However, we suggest that the overarching structure of the model may, nonetheless, be transferable. That is, although it may not be (for example) school timetabling that prevents teachers in another context from receiving the intended professional development, something in that other context may nonetheless act as a barrier or filter between intended and received professional development. Likewise, although the specific acceptance barriers in other contexts may differ, such barriers may, nonetheless, exist. Investigating the transferability of the overarching structure of the conceptual model for other geographic contexts is an important direction for future research.

At the same time, however, consideration of past literature suggests that some of the specific barriers highlighted in this study may be relevant elsewhere, given that they are in alignment with international research findings. While we cannot claim that our findings are directly generalisable given the interpretivist and contextually-situated nature of our study, below we consider how the issues raised in this study relate to the findings of existing literature. We also identify relevant directions for future research.

\section{Integration and Extensions of Existing Literature}

Although the importance of context in influencing professional development has previously been widely acknowledged (Day and Gu 2007, Timperley et al. 2007, Desimone 2009, Opfer and Pedder 2011), our findings provide new specificity regarding how the previously poorly defined 'context' variable can affect the outcomes of professional development. All of the structural and acceptance barriers identified in the present study reflect contextual influences-features of the school context, policy context or personnel involved rather than, for example, the design or delivery of the professional development itself. Our study thus provides insights into what may be some relevant contextual factors (in our study's particular context) and how these factors can act as gatekeepers or filters in the 
professional development-to-impact trajectory. Understanding these elements is important because 'the impact of professional learning, both positive and negative, cannot be felt or seen in a vacuum' (Fraser et al. 2007, p. 160).

The access barriers identified in this study—namely, language issues and schoolrelated factors - highlight the importance of school leaders' role in ensuring that intended professional development is implemented and accessible for all teachers. In other contexts, it may be that different specific factors constitute barriers to teachers' access to professional development. However, we suggest that it is nonetheless important for school leaders to be attentive to (and work to pre-empt or resolve) whatever might restrict teachers' access to professional development in their specific setting. Other educational reform literature has emphasised the crucial role of school leaders in managing change within their school sites (Pont et al. 2008, Robinson et al. 2009, Harris and Jones 2017), but our study has illustrated ways in which this aspect of the organisational context specifically relates to teacher professional development efforts. Future research could seek to further investigate this interaction.

On the other hand, the acceptance barriers identified in this study_cognitive access to professional development, the contextual fit of professional development and matters of teacher agency_-highlight the importance of teachers' active role in managing their professional development, affecting the potential for teaching and learning impacts. This active participation appears to happen at (at least) two moments: the constructing of meaning as teachers make sense of new ideas, and then the critiquing and acceptance (or rejection) of those ideas. Because these are both internal teacher processes and were evident in our sample of teachers from 15 nationalities, we suggest that this finding may well be relevant in a range of geographic contexts. Future research should explore this possibility. 
In terms of teachers' active role in constructing meaning, research involving sensemaking theory has previously highlighted the active cognitive process whereby teachers make sense of policy messages, teaching approaches and reform initiatives (Rosebery and Puttick 1998, Coburn 2001, McArdle and Coutts 2010, Wallace and Priestley 2011, Allen and Penuel 2015). The present study has illustrated what can happen if teachers do not have the opportunities or abilities that afford adequate sensemaking: In this study, the lack of cognitive access formed a barrier to the Arab teachers' acceptance and subsequent implementation of the ideas, strategies and philosophies contained within professional development. While the specific manifestations of cognitive access issues may vary in different contexts, the accounts of the teachers in the present study resonate with Timperley et al.'s (2007, p. 7, emphasis added) statement that

The extent to which new information is used [by teachers] is strongly influenced by the extent to which conceptual understandings and practical resources offered through the learning experience make sense to the recipients in terms of their existing understandings and practice contexts.

Even once (or if) teachers have made sense of the ideas and strategies involved in professional development, the present study indicated that teachers then exercise agency in considering whether these ideas and strategies fit their teaching context or align with their existing philosophies, beliefs and practices. Much existing literature has emphasised the importance of acknowledging and promoting teacher agency in the context of teacher professional development (Kennedy 2005, Bill \& Melinda Gates Foundation 2014, Kennedy 2014, King 2014, Boylan et al. 2017, Harris and Jones 2017, Vähäsantanen et al. 2017). The present study advances the field by incorporating, for the first time, matters of teacher agency into a theoretical model of the professional development-to-impact trajectory. The study also demonstrated how, in a specific context, matters of teacher agency affected the impact of 
teacher professional development. Specifically, teachers exercised their agency to reject (rather than accept) professional development that they felt was unnecessary, irrelevant, inappropriate or that they felt did not honour their existing professional expertise. The teachers' use of agency aligns with Vähäsantanen et al.'s (2017, p. 518) suggestion that 'the manifestations of professional agency are not always proactive and developmental; indeed, agency also includes forms of resistance towards external norms and reforms, and of maintenance of professional practices and identities.' Future research should consider whether teacher agency is exercised in similar ways in relation to professional development in other contexts.

\section{Implications for Practice}

This study offers three main implications for teacher professional development practice. First, our identification of structural barriers highlights the need for school leaders to actively monitor and seek to minimise any issues that may be preventing teachers from accessing intended professional development. Such barriers may include, but are likely to not be limited to, the barriers identified in this study: school-related factors (school timetabling, the school's physical location and teachers' assigned grade levels or teaching subjects) and language barriers.

Second, this study highlights the need to acknowledge teachers as adult learners and as professionals who seek to be respected and offered agency in their own professional learning journey. One-size-fits-all professional development or initiatives that omit consultation and partnership with teachers may be frustrated due to teachers' agency in rejecting the received professional development and the associated reform intentions.

Third, our study raises questions around the 'gap' between teachers' present beliefs, understandings, philosophies and practices and those that are advocated within professional development. Previous research has noted the importance of cognitive dissonance for 
prompting deep change in teachers' beliefs and practice (Loucks-Horsley and Matsumoto 1999, Timperley et al. 2007, Stoll et al. 2012, Allen and Penuel 2015). However, our research along with that of Coburn (2001) and Timperley et al. (2007) indicates that if this dissonance or cognitive access gap is too great, teachers may dismiss the new ideas completely. Thus, the 'Goldilocks principle' seems to apply here: too little dissonance between old and new ideas and teachers are not prompted to learn or change; too much dissonance and teachers either are unable to make sense of the new ideas or make sense of but reject the new ideas - in either case, failing to learn or change. A level of dissonance that is 'just right' seems necessary; professional development facilitators face a clear challenge in balancing this consideration with the need for teacher agency discussed above.

\section{Limitations}

Given the interpretivist stance taken for this study, it is important to reinforce that the findings are context-specific. Our intention was not to capture a universally-applicable set of influences or factors that reflect what makes professional development 'work' across all contexts. Rather, we sought to understand and interpret teachers' accounts of how this process worked in the specific context of Abu Dhabi public schools. Although there may be findings that are applicable elsewhere, the transferability of interpretivist research findings to other contexts depends on the degree of similarity between the research context and any proposed contexts in which the findings may be applied (Lincoln and Guba 1986, Willis 2007).

The results of this study are also grounded in the subjective accounts and constructions of meaning that were expressed by teachers. Teachers' perceptions and accounts of their classroom practice or their existing knowledge and expertise may not align with objective observations of these matters; indeed, teachers in the present study hinted at this issue, such as in the following remark: 
[Teachers in my school] had misunderstandings, for example, about differentiation - they said, 'Yes, we know, we've had it before, we've talked about it so many times before'-but when you visit their classrooms, there is no differentiation in the classrooms. So, they don't understand it, and they don't think they need to know more. (Int-Ar-14)

In one sense, this is a limitation in terms of the 'objectivity' of the research. However, the present study has demonstrated how the teachers' perceptions - accurate or otherwise — of their own expertise affected their attitudes toward (and, therefore, the impact of) professional development. For more objective studies of teacher professional development in Abu Dhabi at the time this study was conducted, we refer readers to Badri et al. (2017) and Von Oppell and Aldridge (2015).

In terms of the comprehensiveness of the study's findings, it was disappointing that the data collected did not shed light on the specific nature of any implementation or student impact barriers. Timperley et al. (2007) have previously noted that there are unknown factors at play_-depicted in their work as 'black boxes'—both before and after changes in teachers' classroom practice (corresponding to our implementation and student impact barriers). However, at the time that the data were collected for this study, the importance of these various barriers had not yet been identified and the conceptual model shown in Figure 2 had not yet been developed. As such, we did not have the opportunity to deliberately elicit data that would 'fill out' our understanding of these types of barriers. Exploring and identifying these implementation and student impact barriers is an important direction for future research.

\section{Conclusion}

It is in the nature of models to be incomplete, over-simplistic or limited in application. Like the statistician George Box (1979, p. 2), however, we take the view that 'all models are 
wrong — but some are useful.' Existing models of the teacher development process each offer us partial understanding of the complex process by which teacher professional development activities influence teachers, teaching and student outcomes. In this article, we have offered a new model that complements and extends past models. Whereas past models emphasised the ideal or intended trajectory from professional development activities to teacher and student impacts (what should happen), our new model uses teacher voice to capture their perceptions of what actually happens. The new model indicates the key points at which contextual factors may act as barriers, 'blocking' the impacts of professional development, and offers examples of what some of the barriers were for the teachers involved in the present study. We believe that the field will benefit from ongoing examination of what teachers (and/or other stakeholders) report actually happens around professional development in a range of different contexts. Such examination may support increased understanding - and hence, ideally, mitigation —of the barriers that can 'get in the way' of professional development's impacts. 


\section{References}

Allen, C.D. \& Penuel, W.R., 2015. Studying teachers' sensemaking to investigate teachers' responses to professional development focused on new standards. Journal of Teacher Education, 66, 136-149.

Badri, M.A. \& Al Khaili, M., 2014. Migration of P-12 education from its current state to one of high quality: The aspirations of Abu Dhabi. Policy Futures in Education, 12, 200220.

Badri, M.A., Al Nuaimi, A., Yang, G., Al Rashedi, A. \& Al Sumaiti, R., 2017. A structural equation model of determinants of the perceived impact of teachers' professional development - The Abu Dhabi application. SAGE Open, 7, 1-18.

Barrera-Pedemonte, F., 2016. High-quality teacher professional development and classroom teaching practices: Evidence from TALIS 2013. Paris: OECD Publishing.

Bates, A., 2013. Transcending systems thinking in education reform: Implications for policymakers and school leaders. Journal of Educational Policy, 28, 38-54.

Bill \& Melinda Gates Foundation, 2014. Teachers know best: Teachers'views on professional development. Seattle: Bill \& Melinda Gates Foundation.

Bishop, R., Berryman, M., Wearmouth, J., Peter, M. \& Clapham, S., 2012. Professional development, changes in teacher practice and improvements in Indigenous students' educational performance: A case study from New Zealand. Teaching and Teacher Education, 28, 694-705.

Box, G.E.P., 1979. Robustness in the strategy of scientific model building. Madison, WI: University of Wisconsin (Madison) Mathematics Research Center.

Boylan, M., Coldwell, M., Maxwell, B. \& Jordan, J., 2017. Rethinking models of professional learning as tools: A conceptual analysis to inform research and practice. Professional Development in Education.

Cameron, S., Mulholland, J. \& Branson, C., 2013. Professional learning in the lives of teachers: Towards a new framework for conceptualising teacher learning. Asia-Pacific Journal of Teacher Education, 41, 377-397.

Charmaz, K., 2000. Constructivist and objectivist grounded theory. In: N.K. Denzin \& Y.S. Lincoln, eds. Handbook of qualitative research. 2nd ed. Thousand Oaks, CA: Sage, 509-535.

Charmaz, K., 2003. Qualitative interviewing and grounded theory analysis. In: J.A. Holstein \& J.F. Gubrium, eds. Inside interviewing: New lenses, new concerns. Thousand Oaks, CA: Sage, 311-330.

Charmaz, K., 2006. Constructing grounded theory: A practical guide through qualitative analysis. London: Sage.

Charmaz, K., 2008. Constructionism and the grounded theory method. In: J.A. Holstein \& J.F. Gubrium, eds. Handbook of constructionist research. New York: Guilford, 397412.

Clarke, D. \& Hollingsworth, H., 2002. Elaborating a model of teacher professional growth. Teaching and Teacher Education, 18, 947-967.

Coburn, C.E., 2001. Collective sensemaking about reading: How teachers mediate reading policy in their professional communities. Educational Evaluation and Policy Analysis, 23, 145-170.

Cohen, L., Manion, L. \& Morrison, K., 2007. Research methods in education, 6th ed. Oxford: Routledge.

Coldwell, M. \& Simkins, T., 2011. Level models of continuing professional development evaluation: A grounded review and critique. Professional Development in Education, 37, 143-157. 
Darling-Hammond, L., Wei, R.C., Andree, A., Richardson, N. \& Orphanos, S., 2009. Professional learning in the learning profession: A status report on teacher development in the United States and abroad. Available from: https://learningforward.org/docs/default-source/pdf/nsdcstudytechnicalreport2009.pdf [Accessed 23 February 2019].

Day, C. \& Gu, Q., 2007. Variations in the conditions for teachers' professional learning and development: Sustaining commitment and effectiveness over a career. Oxford Review of Education, 33, 423-443.

Desimone, L.M., 2009. Improving impact studies of teachers' professional development: Toward better conceptualizations and measures. Educational Researcher, 38, 181199.

Earley, P. \& Porritt, V., 2009. Effective practices in continuing professional development: Lessons from schools. London: Institute of Education.

Earley, P. \& Porritt, V., 2014. Evaluating the impact of professional development: The need for a student-focused approach. Professional Development in Education, 40, 112-129.

Evans, L., 2014. Leadership for professional development and learning: Enhancing our understanding of how teachers develop. Cambridge Journal of Education, 44, 179198.

Fishman, B.J., Marx, R.W., Best, S. \& Tal, R.T., 2003. Linking teacher and student learning to improve professional development in systemic reform. Teaching and Teacher Education, 19, 643-658.

Fraser, C., Kennedy, A., Reid, L. \& Mckinney, S., 2007. Teachers' continuing professional development: Contested concepts, understandings and models. Journal of In-service Education, 33, 153-169.

Garet, M.S., Porter, A.C., Desimone, L.M., Birman, B.F. \& Yoon, K.S., 2001. What makes professional development effective? Results from a national sample of teachers. American Educational Research Journal, 38, 915-945.

Glaser, B.G. \& Strauss, A.L., 1967. The discovery of grounded theory: Strategies for qualitative research. Chicago: Aldine.

Guskey, T.R., 2000. Evaluating professional development. Thousand Oaks, CA: Corwin Press.

Guskey, T.R., 2002. Professional development and teacher change. Teachers and Teaching: Theory and Practice, 8, 381-391.

Harris, A. \& Jones, M., 2017. Leading professional learning: Putting teachers at the centre. School Leadership \& Management, 37, 331-333.

Hill, H.C., Beisiegel, M. \& Jacob, R., 2013. Professional development research: Consensus, crossroads, and challenges. Educational Researcher, 42, 476-487.

Hunzicker, J., 2011. Effective professional development for teachers: A checklist. Professional Development in Education, 37, 177-179.

Kennedy, A., 2005. Models of continuing professional development: A framework for analysis. Professional Development in Education, 40, 336-351.

Kennedy, A., 2014. Understanding continuing professional development: The need for theory to impact on policy and practice. Professional Development in Education, 40, 688697.

King, F., 2014. Evaluating the impact of teacher professional development: An evidencebased framework. Professional Development in Education, 40, 89-111.

King, F., 2016. Teacher professional development to support teacher professional learning: Systemic factors from Irish case studies. Teacher Development, 20, 574-594.

Lincoln, Y.S. \& Guba, E.G., 1986. But is it rigorous? Trustworthiness and authenticity in naturalistic evaluation. New Directions for Program Evaluation, 1986, 73-84. 
Loucks-Horsley, S. \& Matsumoto, C., 1999. Research on professional development for teachers of mathematics and science: The state of the scene. School Science and Mathematics, 99, 258-271.

Mcardle, K. \& Coutts, N., 2010. Taking teachers' continuous professional development (CPD) beyond reflection: Adding shared sense-making and collaborative engagement for professional renewal. Studies in Continuing Education, 32, 201-215.

McChesney, K., 2017. Investigating teachers' experiences of professional development within a major education reform in the emirate of Abu Dhabi. Thesis (PhD). Curtin University. Available from: https://espace.curtin.edu.au/handle/20.500.11937/57566

McChesney, K. \& Aldridge, J.M., 2018. A new tool for practitioner-led evaluation of teacher professional development. Teacher Development, 22, 314-338.

McChesney, K. \& Aldridge, J.M., 2019. A review of practitioner-led evaluation of teacher professional development. Professional Development in Education, 45, 307-324.

OECD [Organisation for Economic Co-operation and Development], 2009. Creating effective teaching and learning environments: First results from TALIS. Paris: OECD.

Opfer, V.D., 2016. Conditions and practices associated with teacher professional development and its impact on instruction in TALIS 2013. Paris: OECD.

Opfer, V.D. \& Pedder, D., 2011. Conceptualizing teacher professional learning. Review of Educational Research, 81, 376-407.

Pont, B., Nusche, D. \& Moorman, H., 2008. Improving School Leadership. Paris: OECD.

Robinson, V., Hohepa, M. \& Lloyd, C., 2009. School leadership and student outcomes: Identifying what works and why. Wellington: New Zealand Ministry of Education.

Rosebery, A.S. \& Puttick, G.M., 1998. Teacher professional development as situated sensemaking: A case study in science education. Science Education, 82, 649-677.

Sachs, J., 2011. Skilling or emancipating? Metaphors for continuing teacher professional development. In: N. Mockler \& J. Sachs, eds. Rethinking educational practice through reflexive inquiry. Dordrecht, The Netherlands: Springer, 153-167.

Seidman, I., 2006. Interviewing as qualitative research: A guide for researchers in education and the social sciences, 3rd ed. New York: Teachers College Press.

Smith, G., 2014. An innovative model of professional development to enhance the teaching and learning of primary science in Irish schools. Professional Development in Education, 40, 467-487.

Stoll, L., Harris, A. \& Handscomb, G., 2012. Great professional development which leads to great pedagogy: Nine claims from research. Available from:

https://assets.publishing.service.gov.uk/government/uploads/system/uploads/attachme nt_data/file/335707/Great-professional-development-which-leads-to-great-pedagogynine-claims-from-research.pdf [Accessed 22 July 2019].

Strauss, A.L. \& Corbin, J., 1994. Grounded theory methodology. In: N.K. Denzin \& Y.S. Lincoln, eds. Handbook of qualitative research. Thousand Oaks, CA: Sage, 273-285.

Supovitz, J.A. \& Turner, H.M., 2000. The effects of professional development on science teaching practices and classroom culture. Journal of Research in Science Teaching, 37, 963-980.

Thorne, C., 2011. The impact of educational reforms on the work of the school principal in the United Arab Emirates. Educational Management Administration \& Leadership, 39, 172-185.

Timperley, H., Parr, J.M. \& Bertanees, C., 2009. Promoting professional inquiry for improved outcomes for students in New Zealand. Professional Development in Education, 35, 227-245. 
Timperley, H., Wilson, A., Barrar, H. \& Fung, I., 2007. Teacher professional learning and development: Best evidence synthesis iteration. Wellington: New Zealand Ministry of Education.

TNTP, 2015. The mirage: Confronting the hard truth about our quest for teacher development. Available from https://tntp.org/assets/documents/TNTPMirage_2015.pdf [Accessed 23 February 2019].

Vähäsantanen, K., Hökkä, P., Paloniemi, S., Herranen, S. \& Eteläpelto, A., 2017. Professional learning and agency in an identity coaching programme. Professional Development in Education, 43, 514-536.

Von Oppell, M.A. \& Aldridge, J.M., 2015. Teacher beliefs and education reform in Abu Dhabi: 21st century skills? MSKU Journal of Education, 2, 36-60.

Wallace, C.S. \& Priestley, M., 2011. Teacher beliefs and the mediation of curriculum innovation in Scotland: A sociocultural perspective on professional development and change. Journal of Curriculum Studies, 43, 357-381.

Willis, J.W., 2007. Foundations of qualitative research. Thousand Oaks, CA: Sage.

Yoon, K.S., Duncan, T., Lee, S.W., Scarloss, B. \& Shapley, K.L., 2007. Reviewing the evidence on how teacher professional development affects student achievement. 